\title{
Ringworm in calves: risk factors, improved molecular diagnosis, and therapeutic efficacy of an Aloe vera gel extract
}

Yasmine H. Tartor ${ }^{1 *}$ (D), Wafaa M. El-Neshwy ${ }^{2}$, Abdallah M. A. Merwad ${ }^{3}$, Mohamed F. Abo El-Maati ${ }^{4}$, Rehab E. Mohamed ${ }^{3}$, Hesham M. Dahshan ${ }^{5}$ and Hala I. Mahmoud ${ }^{6}$

\begin{abstract}
Background: Dermatophytosis in calves is a major public and veterinary health concern worldwide because of its zoonotic potential and associated economic losses in cattle farms. However, this condition has lacked adequate attention; thus, to develop effective control measures, we determined ringworm prevalence, risk factors, and the direct-sample nested PCR diagnostic indices compared with the conventional methods of dermatophytes identification. Moreover, the phenolic composition of an Aloe vera gel extract (AGE) and its in vitro and in vivo antidermatophytic activity were evaluated and compared with those of antifungal drugs.
\end{abstract}

Results: Of the 760 calves examined, 55.79\% (424/760) showed ringworm lesions; 84.91\% (360/424) were positive for fungal elements in direct-microscopy, and 79.72\% (338/424) were positive in culture. Trichophyton verrucosum was the most frequently identified dermatophyte (90.24\%). The risk of dermatophytosis was higher in 4-6-monthold vs. 1-month-old calves (60\% vs. $41 \%$ ), and in summer and winter compared with spring and autumn seasons (66 and 54\% vs. 48\%). Poor hygienic conditions, intensive breeding systems, animal raising for meat production, parasitic infestation, crossbreeding, and newly purchased animals were statistically significant risk factors for dermatophytosis. One-step PCR targeting the conserved regions of the $18 \mathrm{~S}$ and $28 \mathrm{~S}$ genes achieved unequivocal identification of T. verrucosum and T. mentagrophytes in hair samples. Nested-PCR exhibited an excellent performance in all tested diagnostic indices and increased the species-specific detection of dermatophytes by $20 \%$ compared with culture. Terbinafine and miconazole were the most active antifungal agents for dermatophytes. Gallic acid, caffeic acid, chlorogenic acid, cinnamic acid, aloe-Emodin, quercetin, and rutin were the major phenolic compounds of AGE, as assessed using high-performance liquid chromatography (HPLC). These compounds increased and synergized the antidermatophytic activity of AGE. The treated groups showed significantly lower clinical scores vs. the control group $(P<0.05)$. The calves were successfully treated with topical AGE $(500 \mathrm{ppm})$, resulting in clinical and mycological cure within 14-28 days of the experiment; however, the recovery was achieved earlier in the topical miconazole $2 \%$ and AGE plus oral terbinafine groups.

*Correspondence: jasmen21@yahoo.com; yasminehtartor@zu.edu.eg 'Department of Microbiology, Faculty of Veterinary Medicine, Zagazig University, Zagazig 44511, Egypt

Full list of author information is available at the end of the article

C The Author(s). 2020 Open Access This article is licensed under a Creative Commons Attribution 4.0 International License, which permits use, sharing, adaptation, distribution and reproduction in any medium or format, as long as you give appropriate credit to the original author(s) and the source, provide a link to the Creative Commons licence, and indicate if changes were made. The images or other third party material in this article are included in the article's Creative Commons licence, unless indicated otherwise in a credit line to the material. If material is not included in the article's Creative Commons licence and your intended use is not permitted by statutory regulation or exceeds the permitted use, you will need to obtain permission directly from the copyright holder. To view a copy of this licence, visit http://creativecommons.org/licenses/by/4.0/ The Creative Commons Public Domain Dedication waiver (http://creativecommons.org/publicdomain/zero/1.0/) applies to the data made available in this article, unless otherwise stated in a credit line to the data. 
(Continued from previous page)

Conclusions: The nested PCR assay provided a rapid diagnostic tool for dermatophytosis and complemented the conventional methods for initiating targeted treatments for ringworm in calves. The recognized antidermatophytic potential of AGE is an advantageous addition to the therapeutic outcomes of commercial drugs.

Keywords: Calves dermatophytosis, Risk factors, Direct-sample nested PCR, Antifungal drugs, Aloe vera gel extract, Treatment

\section{Background}

Fungal infections associated with zoonotic transmission are an important public health problem worldwide [1]. Cattle dermatophytosis is a major public and veterinary health concern, not only because of its high zoonotic impact, but also because of economic losses in cattle farms attributed to hide damage, loss of weight, decimated meat and milk, contagiousness among animals, treatment costs, and difficulty to implement control measures [2, 3]. Ringworm is usually enzootic in cattle herds and is more prevalent in calves [2]. This may be explained by stressors such as rapid growth, weaning, or parasite burden (which weaken their immunity and skin health), as well as close confinement, dietary factors (deficiencies), and production systems [4]. Importantly, Trichophyton verrucosum is the predominant zoophilic dermatophyte causative species of dermatophytosis in cattle and can occasionally spread to humans through direct contact with cattle or infected fomites, causing highly inflammatory skin and hair dermatophytoses [4-6]. Therefore, the development of a precise laboratory test for the identification of dermatophyte species is pivotal for the prevention and effective control of dermatophytoses [2]. In this context, research articles that addressed the prevalence, risk factors, and treatment of calves' ringworm in Egypt are scarce.

Furthermore, literature on the direct molecular diagnostic assays that are used for the detection and identification of dermatophytes in animal clinical samples is lacking [7, $8]$, and there is a need to surpass the time-consuming conventional methods based on microscopy and fungal cultures, which require weeks [8]. The nested polymerase chain reaction (PCR) technique is an effective practical diagnostic approach for dermatophytosis that has helped clinicians initiate rapid and targeted, as opposed to empirical, treatments of animal ringworm [7].

Dermatophytosis in animals remains difficult to eradicate because of antifungal resistance, the scarcity of accessible and authorized antifungal agents for use in veterinary practice, the restricted systemic treatment of livestock because of hepatotoxicity, and drug residues in products consumed by humans [2, 9]. Thus, the discovery of natural, less-toxic, and more-specific therapeutic alternatives is gaining ground. However, the antidermatophytic potential of natural products is plagued by a lack of in vivo studies affirming the antifungal activity of bioactive compounds discovered using in vitro studies [9]. Aloe vera is a plant of the Liliaceae family that has multiple applications, including antifungal, antibacterial, antioxidant, and antiseptic properties and use in cosmetics industries [10]. Nevertheless, the investigations of the in vitro and in vivo antidermatophytic potential of Aloe vera and the determination of its bioactive compounds remain modest.

Hence, this work was designed to investigate (i) the prevalence and risk factors of calves' ringworm in Egypt, (ii) the diagnostic indices of direct nested PCR for the detection and identification of dermatophyte species on hair and scale samples compared with those of the conventional microscopic and culture methods, (iii) the biological activity and phenolic composition of an Aloe Vera gel extract (AGE), (iv) the antifungal activity of AGE in comparison to the antifungal drugs, and (v) the application of AGE for the treatment of calves' ringworm.

\section{Results}

Prevalence of dermatophytosis among clinically examined calves

On clinical examination, 55.79\% of calves (424/760) showed grayish-white, crusty, circular, and circumscribed discrete lesions (Additional Fig. 1A); moreover, alopecic, erythematous areas that remained after the removal of raised greasy crusts were observed occasionally (Additional Fig. 1B). The skin lesions were mostly found on the head and neck (46.69\%) and all over the body (44.81\%). Some cases $(8.49 \%)$ also had lesions on the head, neck, and trunk. The degree of infection varied from moderate (55.18\%) to severe (44.81\%).

Direct microscopic observation of skin scrapings and hair samples revealed the presence of ectothrix arthroconidia in $84.91 \%(360 / 424)$ of samples, whereas, $79.72 \%$ (338/424) were positive for mycological culture. Fungal culture resulted in the identification of $T$. verrucosum (90. 24\%) and T. mentagrophytes (9.76\%) from the infected animals.

\section{Potential risk factors for calves' ringworm}

As revealed in Table 1, there was a highly significant $(P<0.001)$ association between ringworm infection and the investigated risk factors. A significant effect of age was showed on likelihood of ringworm infection as the 
Table 1 Final logistic regression model of potential risk factors significantly $(P<0.05)$ associated with ringworm infection in calves

\begin{tabular}{|c|c|c|c|c|c|c|c|}
\hline \multirow[t]{2}{*}{ Risk factor } & \multicolumn{2}{|l|}{ Calves } & \multirow{2}{*}{$\begin{array}{l}\text { Prevalence } \\
(\%)\end{array}$} & \multirow[t]{2}{*}{$\beta^{a}$} & \multirow[t]{2}{*}{ S.E. $(\beta)$} & \multirow{2}{*}{$\begin{array}{l}\mathrm{OR}^{\mathrm{b}} \\
(95 \% \mathrm{Cl})\end{array}$} & \multirow{2}{*}{$\begin{array}{l}\text { Relative risk } \\
(95 \% \mathrm{Cl})\end{array}$} \\
\hline & Infected & Non-infected & & & & & \\
\hline \multicolumn{8}{|l|}{ Age } \\
\hline 1 month (ref.) & 66 & 97 & 40.49 & & & & \\
\hline $4-6$ months & 358 & 239 & 59.97 & 0.789 & 0.18 & $2.201(1.546-3.133)$ & $1.481(1.215-1.804)$ \\
\hline \multicolumn{8}{|l|}{ Breed } \\
\hline Pure breed (ref.) & 297 & 312 & 48.77 & & & & \\
\hline Crossbreed & 127 & 24 & 84.11 & 1.715 & 0.236 & $5.558(3.494-8.843)$ & 1.724 (1.549-1.919) \\
\hline \multicolumn{8}{|l|}{ Season } \\
\hline Summer (ref.) & 190 & 100 & 65.52 & & & & \\
\hline Winter & 81 & 69 & 54 & -0.48 & 0.205 & $0.617(0.413-0.923)$ & $0.824(0.695-0.976)$ \\
\hline Spring & 83 & 90 & 47.98 & -0.72 & 0.196 & $0.485(0.331-0.713)$ & $0.732(0.614-0.873)$ \\
\hline Autumn & 70 & 77 & 47.62 & -0.74 & 0.206 & $0.478(0.319-0.716)$ & $0.726(0.601-0.878)$ \\
\hline \multicolumn{8}{|l|}{ Area per calf } \\
\hline Overcrowding (1.5 m/calf) (ref.) & 194 & 120 & 61.78 & & & & \\
\hline No overcrowding (6 m/calf) & 230 & 216 & 51.57 & -0.42 & 0.149 & $0.659(0.491-0.884)$ & $0.834(0.736-0.945)$ \\
\hline \multicolumn{8}{|l|}{ Ventilation } \\
\hline Good (ref.) & 295 & 315 & 48.36 & & & & \\
\hline Bad & 129 & 21 & 86 & 1.88 & 0.248 & 6.559 (4.027-10.683) & $1.778(1.602-1.973)$ \\
\hline \multicolumn{8}{|l|}{ Production system } \\
\hline Milk (ref.) & 282 & 318 & 47 & & & & \\
\hline Meat & 142 & 18 & 88.75 & 2.185 & 0.263 & 8.896 (5.310-14.902) & $1.888(1.706-2.089)$ \\
\hline \multicolumn{8}{|l|}{ Breeding system } \\
\hline Semi-intensive (ref.) & 305 & 297 & 50.66 & & & & \\
\hline Intensive & 119 & 39 & 75.32 & 1.089 & 0.202 & $2.971(2.001-4.412)$ & $1.486(1.319-1.674)$ \\
\hline \multicolumn{8}{|l|}{ Origin of the animals } \\
\hline Born at the farm (ref.) & 302 & 313 & 49.11 & & & & \\
\hline Newly purchased & 122 & 23 & 84.14 & 1.704 & 0.241 & $5.497(3.426-8.820)$ & 1.713 (1.539-1.907) \\
\hline \multicolumn{8}{|l|}{ Parasitic infestation } \\
\hline Absent (ref.) & 312 & 278 & 52.88 & & & & \\
\hline Present & 112 & 58 & 65.88 & 0.542 & 0.181 & $1.720(1.205-2.456)$ & $1.245(1.091-1.422)$ \\
\hline \multicolumn{8}{|l|}{ Use of disinfectant } \\
\hline Irregular (ref.) & 125 & 27 & 82.24 & & & & \\
\hline Regular & 299 & 309 & 49.18 & -1.57 & 0.227 & $0.209(0.133-0.326)$ & $0.598(0.536-0.667)$ \\
\hline
\end{tabular}

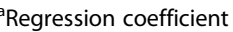

${ }^{\mathrm{b}}$ Odds ratio

risk of infection was 2.201 times higher in 4-6-monthold animals vs. younger calves with relative risk ratio 1.481. Meanwhile, crossbred animals were more likely (5.558 times higher) to be infected compared to purebred ones with relative risk ratio 1.724 .

The highest risk of calves' dermatophytosis was observed in summer and winter compared with spring and autumn seasons (65.5 and $54 \%$ vs. $48 \%$ ). During winter, spring, and autumn seasons, the animals were less likely to be infected compared with summer season with risk ratios $0.824,0.732$ and 0.726 , respectively. The risk of infection in intensive breeding system, newly purchased animals introduced to the farm, and conditions of parasitic infestation was higher (2.971, 5.497, and 1.720 times, respectively) compared with semi-intensive breeding system, the animals born at the farm, and the absence of parasitic infestation with relative risk $1.486,1.713$, and 1.245 , respectively. The bad ventilation resulted in significant increase (6.559 times) in the likelihood of ringworm 
infection compared to the good ventilation with risk ratio 1.778 . The area available per calf highly affected the infection potential. A narrower area $\left(1.5 \mathrm{~m}^{2} /\right.$ calf $)$ led to a greater spread of skin lesions among the animals; however, the likelihood of ringworm infection for no overcrowding $\left(6 \mathrm{~m}^{2} /\right.$ calf $)$ decreased 0.659 times and the risk ratio was 0.834 . Ringworm lesions were 8.896 times more likely in animals reared for meat production compared with animals reared for milk production with risk ratio 1.88. Also, regular use of disinfectant decreased the likelihood of ringworm infection significantly (0.209 times) compared with irregular system with risk ratio 0.589 .

The random forest classification model and box plot (Fig. 1a and b) confirmed this observation, i.e. the age of calves was the most important risk factor, followed by the production system, presence of parasitic infestation, and irregular use of disinfectant was the fourth most risk factor.

\section{Nested PCR for the detection and identification of dermatophytes in clinical samples}

Pan-dermatophyte, one-step and nested PCR methods were evaluated in the context of dermatophyte identification in 75 samples that were direct microscopy and culture-positive, 36 samples that were positive by microscopy alone, nine samples positively diagnosed by culture alone, and 30 negative samples. The Pan-dermatophyte PCR could specifically detected dermatophyte DNA in 58\%; one-step PCR did so in $62 \%$; and nested PCR was positive in $72 \%$ of 150 samples (Table 2) with $440 \mathrm{bp}$ pchs- 1 amplicons, $~ 900 \mathrm{bp}$ ITS+ amplicons, and 400 bp ITS- 1 amplicons, respectively (Fig. 2 a, b, and c).

Nested PCR increased the species-specific detection of dermatophytes by 20 and $10 \%$ compared with culture alone or the combination of culture and direct microscopy, respectively.

Fungal culture identified dermatophytes in 56\% (84/150), whereas direct microscopy identified dermatophytes in $74 \%$ $(111 / 150)$ of samples. Out of the 66 samples that were negative for dermatophytes in culture, non- dermatophyte molds were cultured from 21 samples that were test-positive only by one-step PCR. In addition, non-dermatophyte molds were co-cultured with dermatophytes from six samples that were negative in the pan-dermatophyte, one-step, and nested PCRs.

As depicted in Table 3 the performance of the nestedPCR assay was excellent regarding all diagnostic indices tested. Using fungal culture as a reference standard, sensitivities of 82.14 and $71.43 \%$ and specificities of 72.73 and $50 \%$ were recorded for pan-dermatophyte and onestep PCR, respectively, whereas the corresponding values

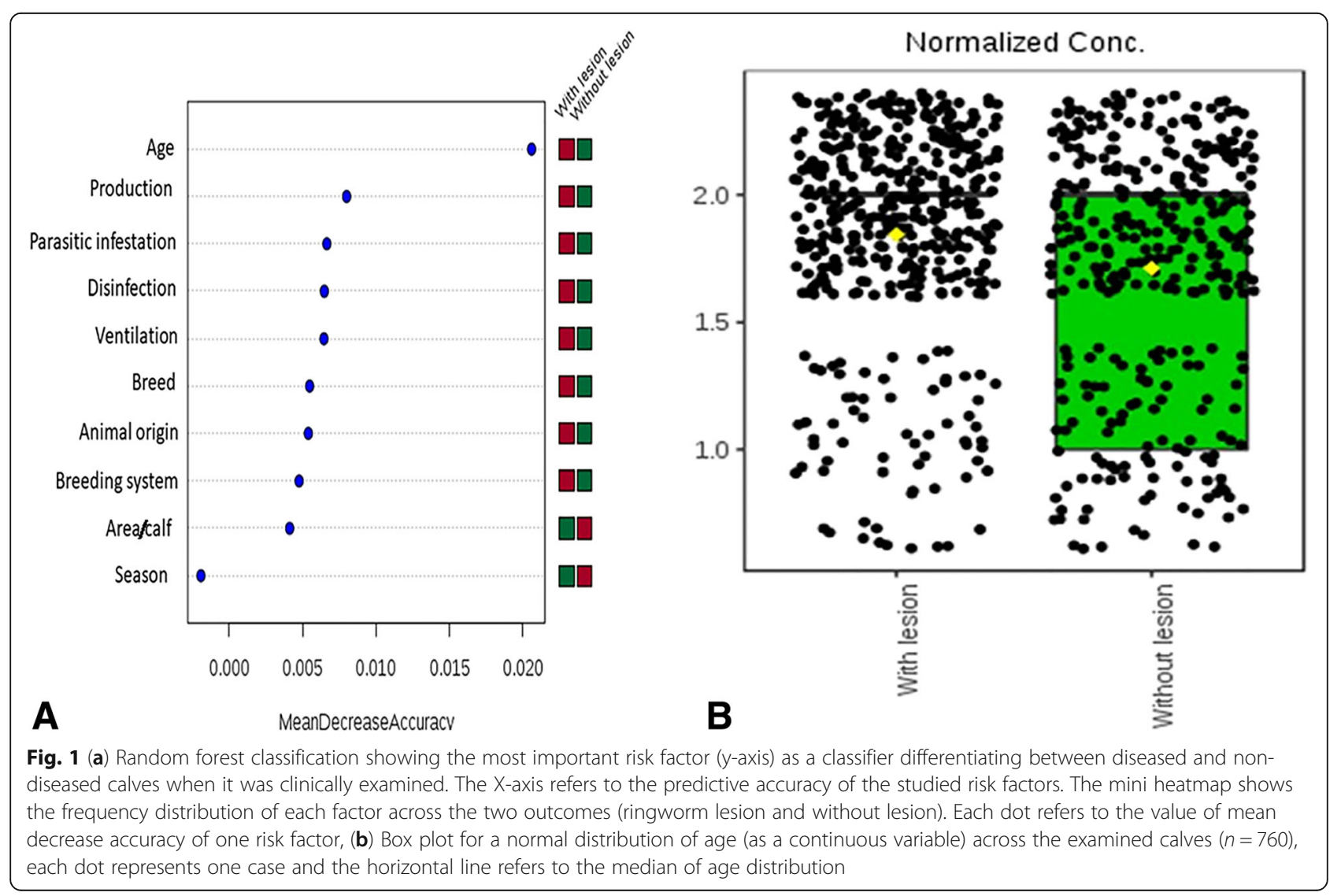


Table 2 Results of direct microscopy, culture, and direct sample-PCR assays for the detection and identification of dermatophytes in 150 scales and hair samples

\begin{tabular}{|c|c|c|c|c|c|}
\hline Direct microscopy & Dermatophyte culture & $\begin{array}{l}\text { aPan-dermatophyte } \\
\text { PCR }\end{array}$ & ${ }^{\mathrm{b}}$ One-step PCR & Nested-PCR & $\begin{array}{l}\text { Frequency } \\
(\%)\end{array}$ \\
\hline $\begin{array}{l}\text { [No. positive = } 111 \\
(74 \%)]\end{array}$ & $\begin{array}{l}\text { [No. positive }=84 \\
(56 \%)]\end{array}$ & $\begin{array}{l}\text { [No. positive }=87 \\
(58 \%)]\end{array}$ & $\begin{array}{l}\text { [No. positive }=93 \\
(62 \%)]\end{array}$ & $\begin{array}{l}\text { [No. positive }=108 \\
(72 \%)]\end{array}$ & \\
\hline+ & + & + & + & + & $51(34)$ \\
\hline+ & + & - & - & - & $6(4)$ \\
\hline+ & + & + & - & + & $9(6)$ \\
\hline+ & + & - & - & + & $9(6)$ \\
\hline+ & - & + & + & + & $6(4)$ \\
\hline+ & - & - & - & - & $15(10)$ \\
\hline+ & - & - & + & - & $6(4)$ \\
\hline+ & - & + & - & + & $3(2)$ \\
\hline+ & - & - & - & + & $6(4)$ \\
\hline- & + & + & + & + & $9(6)$ \\
\hline- & - & + & + & + & $6(4)$ \\
\hline- & - & + & - & + & $3(2)$ \\
\hline- & - & - & + & - & $15(10)$ \\
\hline- & - & - & - & + & $6(4)$ \\
\hline
\end{tabular}

Representative ${ }^{a}$ pchs- 1 and ${ }^{b}$ ITS + amplicons were sequenced for confirmation of the dermatophytes identification results. GenBank accession numbers of the nucleotide sequences were mentioned in the methods section

were 92.86 and $54.55 \%$ for nested PCR. In contrast, using the combination of culture and nested PCR as the gold standard, nested PCR was superior to the other methods as it achieved a sensitivity value of $94.74 \%$, whereas culture and direct microscopy exhibited sensitivities of 73.68 and $78.95 \%$, respectively. Specificity and PPVs were $100 \%$ for nested PCR and culture; therefore, they were considered as the gold standard, while the corresponding values were 41.67 and $81.08 \%$ for direct microscopy. Nested PCR was very accurate (AUC $=96 \%$ ), whereas pan-dermatophyte PCR (82\%) and culture (80\%) were moderately accurate. A lower diagnostic accuracy was recorded for the direct microscopy and one-step PCR $(50<\mathrm{AUC} \leq 70 \%)$. The diagnostic odds ratio (DOR) of nested PCR is much higher than that of any other test which implies that the diagnostic performance of nested PCR was the best and was in strong agreement with the results obtained using culture and nested PCR results (Kappa value $=0.91$ and $P<0.001$ ).

Confirmatory DNA sequencing for the representative ITS+ and pchs-1 amplicons was performed, and the BLAST search of the resulting sequences produced hits that corresponded to T. verrucosum and T. mentagrophytes sequences available in the GenBank.

\section{Susceptibility of dermatophytes to antifungal drugs}

The minimum inhibitory concentration (MIC) values of the five antifungal drugs for T. verrucosum and T. mentagrophytes are presented in Additional Table 1. The comparison of the values of the five antifungals for the two species tested revealed that those obtained for terbinafine were the lowest, followed by miconazole (MIC range, $0.03-0.25,0.03-1 \mu \mathrm{g} / \mathrm{mL} ; 0.06-0.5,0.03-0.5 \mu \mathrm{g} /$ $\mathrm{mL}$, respectively). Moreover, the $\mathrm{MIC}_{50}$ and $\mathrm{MIC}_{90}$ values of terbinafine and miconazole were the lowest when compared with those of other antifungals. The mean MIC values \pm SD of the tested antifungal agents did not differ between $T$. verrucosum and $T$. mentagrophytes $(P>0.05)$. Fluconazole was the least effective drug, with an overall MIC range of 8-64 $\mu \mathrm{g} / \mathrm{mL}$.

\section{Yield, TPC, TF, phenolic compounds, antioxidant and antifungal activity of AGE}

As depicted in Table 4 the AGE yield was $1.02 \mathrm{~g}$ extract of $100 \mathrm{~g}^{-1}$. The amount of total phenolic compounds in AGE was $111.78 \mathrm{mg}$ of gallic acid equivalent (GAE) $\mathrm{g}^{-1}$ of gel. The flavonoid content of the extract was $45.6 \mathrm{mg}$ of quercetin equivalent $(\mathrm{QE}) \mathrm{g}^{-1}$ of gel. Flavonoids have a broad range of chemical and biological activities, including radicalscavenging properties. For this reason, the extract was analyzed for total phenolic and flavonoid content. The major phenolic compounds of AGE were identified by HPLC and are presented in Table 4. They included gallic acid, caffeic acid, chlorogenic acid, cinnamic acid, aloe-Emodin, quercetin, and rutin. All compounds increased and synergized the antidermatophytic activity of AGE.

The results of the analysis of the 1, 1-Diphenyl2picrylhydrazyl $\left(\mathrm{DPPH}^{\circ}\right)$ radical-antioxidant activities of 


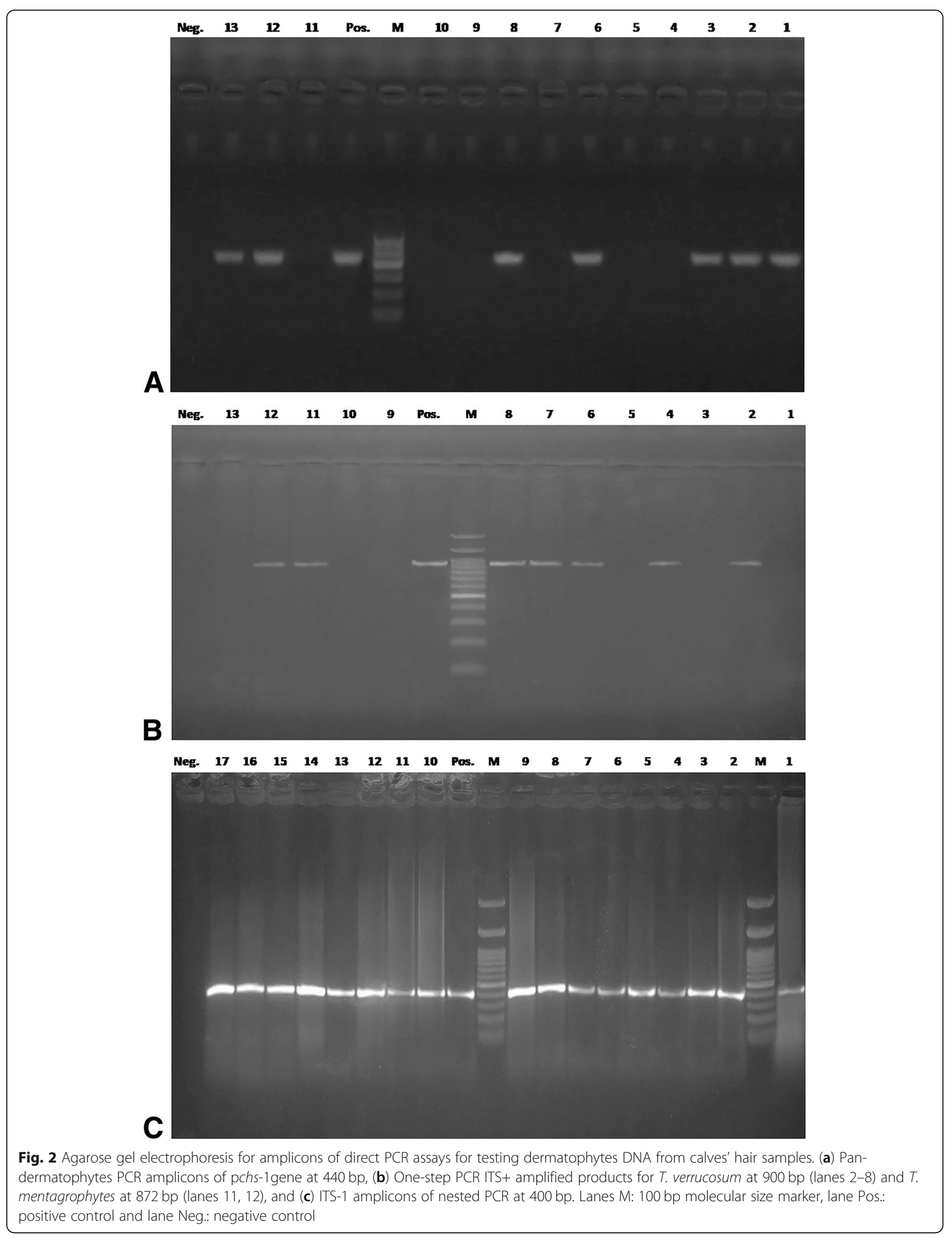


Table 3 Diagnostic indices of the direct-sample PCRs for the detection and identification of dermatophytes from ringworm lesions based on (a) culture and (b) culture and/or nested PCR as the gold standards

\begin{tabular}{|c|c|c|c|c|}
\hline Diagnostic index $^{a}$ & Pan-dermatophyte & One step-PCR & Nested PCR & \\
\hline \multicolumn{5}{|c|}{ Culture as the gold standard } \\
\hline Se $(95 \% \mathrm{Cl})$ & $82.14 \%$ (72.26-89.65) & $71.43 \%(60.53-80.76)$ & $92.86 \%(85.10-97.33)$ & \\
\hline SP $(95 \% \mathrm{Cl})$ & $72.73 \%(60.36-82.97$ & $50 \%(37.43-62.57)$ & $54.55 \%(41.81-66.86)$ & \\
\hline PPV $(95 \%$ Cl) & $79.31 \%(71.86-85.20)$ & $64.52 \%(57.96-70.57)$ & $72.22 \%(66.48-77.32)$ & \\
\hline NPV $(95 \% \mathrm{Cl})$ & $76.19 \%(66.40-83.82)$ & $57.89 \%(47.58-67.56)$ & $85.71 \%(72.91-93.05)$ & \\
\hline $\mathrm{LR}+(95 \% \mathrm{Cl}$ & $3.01(2.01-4.52)$ & $1.43(1.08-1.88)$ & $2.04(1.56-2.68)$ & \\
\hline LR- $(95 \%$ Cl) & $0.25(0.15-0.40)$ & $0.57(0.38-0.87)$ & $0.13(0.06-0.29)$ & \\
\hline DOR (95\% Cl) & $12.36(5.64-26.7)$ & $2.5(1.72-4.19)$ & $15.6(5.965-40.799)$ & \\
\hline AUC & $78 \%(70.51-84.35)$ & $62 \%(53.72-69.79)$ & $76 \%(68.35-82.59)$ & \\
\hline \multirow[t]{2}{*}{ Kappa value } & $0.55^{* * *}$ & $0.217^{* *}$ & $0.493^{* * *}$ & \\
\hline & Direct microscopy & Culture & One step-PCR & Nested PCR \\
\hline \multicolumn{5}{|c|}{ Nested PCR and Culture as the gold standard } \\
\hline Se $(95 \% \mathrm{Cl})$ & $78.95 \%(70.31-86.02)$ & $73.68 \%(64.61-81.49)$ & $63.16 \%(53.61-72.00)$ & $94.74 \%(88.90-8.04)$ \\
\hline SP $(95 \% \mathrm{Cl})$ & $41.67 \%(25.51-59.24)$ & $100 \%(90.26-100)$ & $41.67 \%(25.51-59.24)$ & $100 \%(90.26-100)$ \\
\hline PPV $(95 \%$ Cl) & $81.08 \%(76.19-85.16)$ & $100 \%$ & $77.42 \%(71.56-82.37)$ & $100 \%$ \\
\hline NPV $(95 \% \mathrm{Cl})$ & $38.46 \%(26.99-51.38)$ & $54.55 \%(46.88-62)$ & $26.32 \%(18.47-36.02)$ & $85.71 \%(73.36-92.89)$ \\
\hline $\mathrm{LR}+(95 \% \mathrm{Cl}$ & $1.35(1.01-1.81)$ & b & $1.08(0.79-1.48)$ & b \\
\hline LR- $(95 \% \mathrm{Cl})$ & $0.51(0.30-0.85)$ & $0.26(0.19-0.36)$ & $0.88(0.56-1.39)$ & $0.05(0.02-0.11)$ \\
\hline DOR (95\% Cl) & $2.68(1.2-5.9)$ & $0.46(0.35-0.59)$ & $1.22(0.57-2.62)$ & $19.6(8.7-41.4)$ \\
\hline AUC & $70 \%(61.99-77.20)$ & $80 \%(72.70-86.08)$ & $58 \%(49.68-66)$ & $96 \%(91.50-98.52)$ \\
\hline Kappa value & $0.2^{* *}$ & $0.57^{* *}$ & 0.04 & $0.91^{* * *}$ \\
\hline
\end{tabular}

${ }^{a}$ Se Sensitivity, $S p$ specificity, PPV positive predictive value, NPV negative predictive value, $L R+$ positive likelihood ratio, $L R$ - negative likelihood ratio, $D O R$ diagnostic odds ratio and $A U C$ accuracy

${ }^{\mathrm{b}}$ Cannot be estimated/infinity

**, ${ }^{* * *}$ denote significant $P$ values

Table 4 Yield, TPC, TF and phenolic compounds of AGE

\begin{tabular}{lll}
\hline & Unit & 'AGE \\
\hline Extract yield & g/100 g Aloe vera gel & $1.02 \pm 0.052$ \\
${ }^{\mathrm{a}}$ TPC & $\mathrm{mg} \mathrm{GAE} / \mathrm{g}$ extract & $111.78 \pm 10.62$ \\
${ }^{\mathrm{b}}$ TF & $\mathrm{mg} \mathrm{QE} / \mathrm{g}$ extract & $45.6 \pm 8.45$
\end{tabular}

Phenolic compounds

\begin{tabular}{|c|c|}
\hline $\mathrm{mg} / \mathrm{g}$ AGE & $0.12 \pm 0.06$ \\
\hline Caffeic acid & $0.23 \pm 0.11$ \\
\hline Chlorogenic acid & $0.54 \pm 0.07$ \\
\hline Cinnamic acid & $0.98 \pm 0.25$ \\
\hline Aloe-Emodin & $28.02 \pm 4.67$ \\
\hline Quercetin & $1.54 \pm 0.22$ \\
\hline Rutin & $1.14 \pm 0.86$ \\
\hline
\end{tabular}

${ }^{\mathrm{a}} T P C$ Total phenolic compounds, GAE gallic acid equivalent, ${ }^{\mathrm{b}} T F$ total flavonoids, $Q E$ quercetin equivalent and ' $A G E$ Aloe vera gel extract
AGE are depicted in Fig. 3a and were as follows: antioxidant activity of $85.3 \%$ for AGE, $92.2 \%$ for gallic acid, and $88.6 \%$ for Tert-butyl hydroquinone (TBHQ) after $2 \mathrm{~h}$ of reaction. The results obtained demonstrated that this extract has antioxidant activity. As revealed in Fig. 3a, AGE inhibited the bleaching of $\beta$-carotene by scavenging linoleate-derived free radicals. The efficacy of the compounds was as follows (in decreasing order): TBHQ > AGE $>$ gallic acid. The analysis showed a comparable scavenging ability between AGE (72.3\%) and the synthetic antioxidants gallic acid (65.7\%) and TBHQ (81.22\%). AGE displayed a ferric reducing antioxidant power (FRAP) that was comparable to that of TBHQ and gallic acid (Fig. 3b). The FRAP of AGE was 1.96 vs. 2.23 for gallic acid and 2.57 for TBHQ. AGE exhibited an inhibitory effect for $T$. verrucosum and $T$. mentagrophytes at MIC values ranging from 300 to $400 \mathrm{ppm}$ and 400 to $500 \mathrm{ppm}$, respectively.

\section{Effectiveness of AGE in the eradication of $T$. verrucosum from calves}

In the treated calves, gradual improvement of the lesions was observed within 7-12 days post-treatment. Complete clinical 

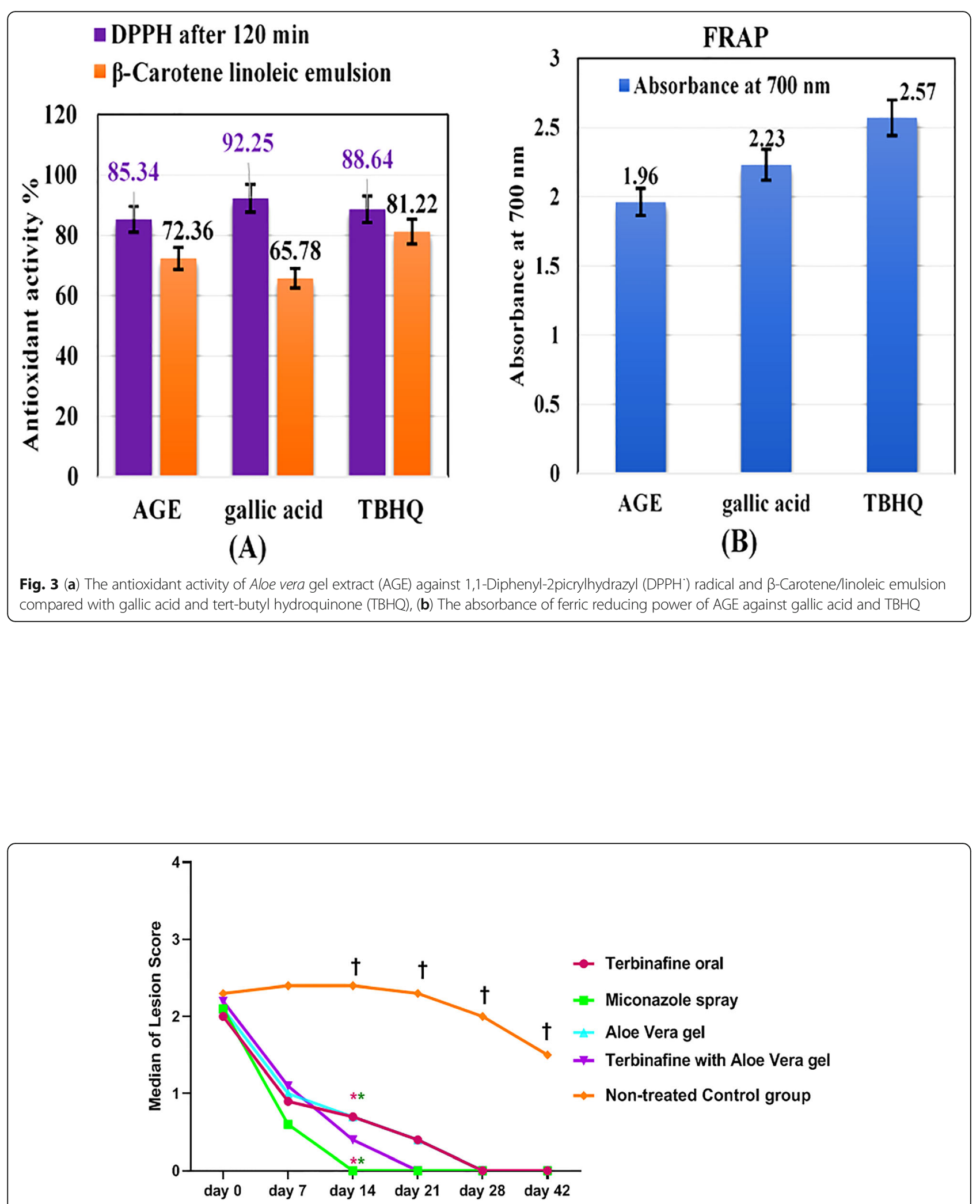

Fig. 4 Medians for clinical scores of ringworm lesions on treated groups and control untreated group from day 0 to 42 days of the study. There is a non-significant difference between the clinical scores of groups on days 0 and 7 , while the treated groups displayed significantly $(P<0.05)$ lower clinical scores than the control group on days 14,21, 28, and 42. Clinical scores carrying asterisks with the same color was statistically different. $\mathbf{t}$ indicating a high significant difference between the control untreated group and all other groups within the same days 
recovery (full hair growth) was observed within 14-19 days after treatment for calves in G2 and G4 and within 21-28 days for animals in G1 and G3 (Additional Fig. 2). In contrast, the lesions detected on the control animals (G5) progressed and did not heal until 42 days of the study.

Direct microscopic examination and fungal cultures yielded negative results within the $4^{\text {th }}$ week of treatment. In contrast, samples from the untreated control calves repeatedly yielded positive mycological results during the investigation period.

As revealed in Fig. 4, the clinical scores of the five animal groups did not differ significantly on days 0 and 7 , while the treated groups showed significantly lower clinical scores than did the control (untreated) group (G5) on days $14,21,28$, and $42(P<0.05)$.

On day 14, a significant improvement in the clinical scores $(P<0.05)$ was detected between miconazole treatment (G2) and the untreated control group (G5), G2 and terbinafine treatment (G1), and G2 and AGE (G3). Moreover, significant changes were detected between terbinafine treatment (G1) and the untreated group (G5) and AGE (G3) and G5 (Fig. 4).

Neither recurrence nor gross side effects were observed throughout the study period or during the clinical follow-up.

\section{Discussion}

An enzootic circumstance of animal dermatophytosis is the outcome of the confinement of animals in breeding and the viability of the arthrospores in the environment for many months [2]. Prevention is difficult, but periodic surveys of the prevalence and risk factors of cattle ringworm may permit the adoption of increasingly effective prophylactic and control measures to prevent infection both to other animals and to humans $[2,11,12]$. In this study, the prevalence rate of ringworm in calves aged 1-6 months was $55.79 \%$, that was nearly identical to that reported in Iran (57.5\%) [5]. In contrast, the prevalence rate was higher than the $1.6 \%$ documented in Pakistan [12], but lower than the $87.7 \%$ reported in the Tuscany region [4] and the $71.7 \%$ observed in nearby Umbria, in Italy [11]. This discrepancy among countries is perhaps attributable to cattle breed, production, breeding system, origin of the cattle in the farm, and climatic conditions [11]. To answer the question which potential risk factor is most important and would best differentiate between the infected and non-infected clinically examined calves, we depended on the random forest classification model, which best suits doing this task (Fig. 1a) as demonstrated previously [13]. In accordance with other studies [4, 11], the random forest classification and box plot model indicated that age was the most important risk factor, as the risk of infection was higher in calves aged 4-6 month than it was in younger suckling calves (60\% vs. $41 \%)$; and this could be attributed to the stressors of weaning and rapid growth. Furthermore, we found a highly significant correlation between several risk factors found in the examined calf population and ringworm infection, mainly season, bad ventilation, overcrowding, and irregular use of disinfectants. This reinforces the broadly accepted concept that high humidity, close contact between calves, poor hygienic conditions in stables play a significant role in the increase in ringworm prevalence $[4,5,11,12]$. Hence, repeated topical treatment of all infected animals, together with good ventilation and thorough disinfection of stables, halters, fences, cleaning tools, and all of the materials that come into contact with the animals are the basis for the effective control of cattle ringworm [11, 14]. Of interest, there was a highly significant $(P<0.001)$ association between the risk of dermatophytosis and the new introduction of animals to the farm. In support of this finding, Papini et al. [4] debated that calves that are newly introduced into a herd spread the infection to both calves and humans, as they are carriers of dermatophytes before the development of clinical signs.

As described previously $[2,5,11,15]$, the detected clinical signs of cattle dermatophytosis were crusty lesions on the head and neck regions and other parts of the body. However, a study in Tanzania [16] reported occasion detection of the widespread lesions of alopecia and erythema which were also observed here. The detection rates were $84.91 \%$ by direct microscopy and $79.72 \%$ by fungal culture. In this context, inadequate scraping of the lesions and the slow and poor growth of $T$. verrucosum which hampered its detection, are probable explanations for the falsenegative results of direct microscopy and culture, respectively [4]. According to previous studies [11, 15], T. verrucosum is the main dermatophyte causing cattle ringworm, although T. mentagrophytes which is usually associated with the presence of small rodents in farm has also been isolated in this context. The present findings showed that calves' ringworm was caused by $T$. verrucosum in $90.24 \%$ and T. mentagrophytes in $9.76 \%$ of cases. Nevertheless, Aghamirian and Ghiasian [5] isolated T. verrucosum exclusively from 352 infected cows in Iran.

To date, molecular assays have been used for the detection of dermatophytes in clinical samples, as well as confirmation tests of the results of culture [17, 18]. Wollina and coauthors [17] have failed to cultivate T. verrucosum from the sample of a patient with severe tinea barbae. However, real-time PCR and ITS2 sequencing successfully detected $T$. verrucosum. No previous studies have attempted to identify dermatophyte species from hair samples of calves using a nested PCR assay. The findings obtained here revealed that one-step PCR correctly identified $T$. verrucosum and $T$. mentagrophytes in samples that were culture-positive $(n=72 / 150)$, with an amplicon size of $900 \mathrm{bp}$ and $872 \mathrm{bp}$, respectively. In addition, nested PCR amplified ITS + of both species in 
108 samples and produced ITS-1 amplicons of $400 \mathrm{bp}$. This was in agreement with another study [7] that showed that the one step-PCR accurately identified Microsporum canis in hair samples from canines and felines with a band appearing at $922 \mathrm{bp}$, whereas ITS+ amplicons of 851-872 bp were obtained for T. mentagrophytes, T. terrestre, or M. gypseum; moreover, nested PCR achieved unequivocal identification of these species. The highly sensitive nested PCR method also exhibited a high specificity and PPV for detecting additional dermatophyte-positive samples that were missed by culture $(n=30 / 150)$ or by both microscopy and culture $(n=15)$. Other studies highlighted the incorporation of direct PCR in the laboratory diagnosis of onychomycosis for increasing the detection of dermatophyte-positive samples that are culture negative $[19,20]$. A possible explanation for the low specificity and accuracy obtained using one-step PCR compared with pan-dermatophyte and nested PCR is the use of the universal fungal regions of rDNA. Moreover, the low sensitivity of the culture method could be attributed to the overgrowth of nondermatophyte molds in the culture or the dermatophytes cultures were not yet positive after 4 weeks of incubation $[4,7]$. Other reasons are the presence of non-viable fungal material in specimens from treated calves or that the DNA extraction step ease overcoming the impediment of trapping fungus in the keratin [20].

As reported previously [21, 22], terbinafine and miconazole were effective antifungal drugs for dermatophytes followed by itraconazole and griseofulvin; in contrast, fluconazole was the least-active antifungal agent. Recently, Pal [23] recommended the performance of further research for the development of cheap, safe, and potent chemotherapeutic agents for cattle dermatophytosis management. AGE is a cheap, easily obtainable, and safe natural product. Moreover, it is a limitless source of bioactive compounds with recognized antifungal activities that correlate with its antioxidant activities [24]. The results of the three assays used for measuring the antioxidant activity indicate that phenolic compounds have a high antioxidant capacity [25] because of their redox properties, which can play a significant role in the absorption and neutralization of free radicals, decomposition of peroxides, and quenching of singlet and reductive heavy metals with two or more valence states [26]. Phenolic compounds are the active antimicrobial constituents of various plants extract. However, the whole extract has a more noteworthy antifungal activity. Accordingly, AGE might be more advantageous than the isolated components, as the properties of a bioactive individual constituent can change its properties in the presence of other compounds [27]. The additive and synergistic effects of phenolic compounds account for their efficient bioactive properties, which explains why no single antimicrobial agent can supplant the combination of these natural components in achieving the antifungal activity [28]. The antidermatophytic activity of AGE recognized here was inconsistent with the findings of a previous report [29], which showed that the water extract of Aloe vera was effective against T. mentagrophytes. However, no reports exist of the activity of AGE against $T$. verrucosum. Nonetheless, most investigations were performed on fungal isolates, which hampers the extrapolation of the findings to real conditions. Therefore, additional in vivo studies are needed to ensure the reliability of the results [9]. The efficacy of the topical application of AGE for 2 weeks twice daily was compared with topical miconazole $2 \%$, oral terbinafine with topical AGE and once-daily oral terbinafine in proven $T$. verrucosum infected calves. The clinical scores were significantly lower in all treated groups after 14days of treatment compared with the untreated group $(P<0.05)$, whereas complete clinical recovery was achieved earlier in the miconazole group and AGE with oral terbinafine group vs. both the oral terbinafine group and AGE alone group. This indicates that the combination of AGE with oral terbinafine is effective for the treatment of dermatophytosis in calves. The results obtained were comparable with the findings of the treatment of calves with dermatophytosis with topical application of propolis and Whitfield's ointment [30], as well as a polyherbal lotion combined with levamisole and griseofulvin [31].

\section{Conclusion}

This study highlighted the need for good hygienic conditions, regular disinfection of holdings, rapid treatment of infected calves, and examination of the incoming calves to prevent dermatophytic epizoonoses in calves and humans. The implementation of a nested PCR assay provided a rapid diagnostic tool for dermatophytosis and complemented the conventional methods for dermatophytespecies-specific detection for the initiation of targeted treatment, thus reducing the burden of the economic losses caused by ringworm infection. The recognized antidermatophytic potential of AGE is an advantageous addition to commercial drugs and the combination of AGE with oral terbinafine has a potential therapeutic value against ringworm in calves.

\section{Methods \\ Population and collection of clinical samples}

From May 2015 to December 2018, a total of 760 Holstein cow calves (597 weaning and 163 suckling calves) raised in different farms in Egypt, were clinically examined for evidence of ringworm infection. Data about age, breed, farm production, breeding system, production management system, and the origin of calves of the farm were obtained for each calf as potential risk factors. For the 
assessment of parasitic infestation, fecal samples were examined for enteric parasites and thin blood films were prepared, fixed in absolute methyl alcohol, and stained with freshly filtered and diluted 10\% Giemsa stain. After cleaning the skin lesion of the suspected ringwormaffected calf with 70\% ethanol, scales and dull hair samples from the margins were collected using a sterilized plastic hair brush and tweezers, respectively [4].

Portions of hair and scales were examined microscopically after clearing with $20 \%$ potassium hydroxide $(\mathrm{KOH})$, cultured on Mycobiotic Agar $\left(\right.$ Remel $^{\mathrm{Tm}}$, Thermo Fisher Scientific) slants with $10 \%$ thiamine and inositol, incubated at $30^{\circ} \mathrm{C}$ for 4-6 weeks, and observed for growth at 3-day intervals. Dermatophyte isolates were identified according to their macro-and micromorphological characteristics [32].

\section{Extraction of DNA from hair and scale samples and PCR amplification}

The direct molecular identification of dermatophytes was executed in 150 clinical samples that were selected based on the results of direct microscopy and culture analyses. For the high-throughput disruption of samples, $50 \mathrm{mg}$ of hair and scales were placed in a $2 \mathrm{~mL}$ safe-lock tube and incubated overnight at $55^{\circ} \mathrm{C}$ with $360 \mu \mathrm{L}$ of ATL buffer and $20 \mu \mathrm{L}$ of QIAGEN protease (QIAamp DNA Mini kit, Qiagen, Germany, GmbH). Subsequently, tungsten carbide beads were added, and the tubes were placed into the TissueLyser adapter set for disruption using the TissueLyser for $2 \mathrm{~min}$ at $20-30 \mathrm{~Hz}$ twice. DNA extraction was performed using a QIAamp DNeasy Plant Mini kit (Qiagen, Germany, GmbH) according to the manufacturer's instructions. DNA was eluted with $50 \mu \mathrm{L}$ of elution buffer and the concentration was assessed using a NanoDrop ${ }^{\mathrm{TM}} 2000$ spectrophotometer (Thermo Fisher Scientific, Waltham, MA, USA).

\section{One-step PCR}

According to Cafarchia et al. [7] the chitin synthase (pchs-1) gene was amplified using DMTFchsF1 (5-CGAGTACATG TGCTCGCGCAC-3) and DMTFchsR1 (5-CGAGGTCAAA RGCACGCCAGAG-3) primers to assess the presence of dermatophyte amplifiable DNA in the clinical samples. Subsequently, one-step PCR was performed using the primers DMTF18SF1 (5-CCAGGGAGGTTGGAAACGACCG-3) and DMTF28SR1 (5-CTACAAATTACAACTCGGACCC-3), which amplified a $900 \mathrm{bp}$ fragment of the conserved regions in the $18 \mathrm{~S}$ and $28 \mathrm{~S}$ genes, which included the internal transcribed spacer regions of ribosomal DNA (ITS-1, 5.8S, and ITS-2).

\section{Nested PCR}

A nested PCR was applied to amplify $400 \mathrm{bp}$ of a conserved region in the dermatophyte $5.8 \mathrm{~S}$ gene from the ITS+ amplicons of the primary PCR using the
DMTF18SF1 and DMTFITS1R (5-CCGGAACCAAG AGATCCGTTGTTG-3) primers [7].

PCR was performed in an amplification reaction containing $12.5 \mu \mathrm{L}$ of EmeraldAmp Max PCR Master Mix (Takara, Japan), $1 \mu \mathrm{L}$ of each primer $(20 \mathrm{pmol}), 6 \mu \mathrm{L}$ of DNA template in the case of primary PCR or $1 \mu \mathrm{L}$ of diluted product from the primary PCR (dilution, 1:1 with molecular-grade water) for nested PCR and nucleasefree water was added up to $25 \mu \mathrm{L}$. T. verrucosum $\mathrm{ATCC}^{\oplus} 28203^{\mathrm{TM}}$ and an amplification reaction without DNA template were used as a positive and negative control, respectively. Thermocycling conditions described previously [7] were used in an Applied Biosystems 2720 thermal cycler (Thermo Fisher Scientific, USA).

The amplified products were electrophoresed on ethidium-bromide-stained $1.5 \%$ agarose gels (Applichem, Germany, GmbH). A gelpilot $100 \mathrm{bp}$ DNA ladder (Qiagen, Gmbh, Germany) and a 100 bp DNA ladder H3 RTU (Genedirex, Taiwan) were used to determine the amplicon sizes. A gel documentation system (Alpha Innotech, Biometra) was used to photograph the gels and the analysis of the data was performed using a computer software.

\section{DNA sequencing and sequence analysis}

Thirty-seven representative ITS+ and pchs-1 PCR products were purified using the QIAquick PCR Product extraction kit (Qiagen, Valencia) and then sequenced using a Bigdye Terminator V3.1 cycle sequencing kit (Perkin-Elmer) in an Applied Biosystems 3130 genetic analyzer (HITACHI, Japan). DNA sequences were compared with those available in the National Center for Biotechnology Information (www.ncbi. nlm.nih.gov) database using the Basic Local Alignment Search Tool (BLAST). MEGA5 program, product version 5.1 (www. megasoftware.net) was used for sequence analysis. The ITS sequences were available under the GenBank accession numbers MK918485, MK918486, MT261760-MT261763, MT261765-MT261768, MT260175, MT260404, MT260449, MT260803, MT260878, MT261110, MT261113, MT261177, MT261197, MT261198, MT261202, MT261203, MT261385, MT261616, MT261746, MT261759, and MT269023. In addition, MT273253- MT273262 were for pchs-1 gene sequences.

\section{Antifungal susceptibility testing of dermatophytes isolates}

The broth micro-dilution method (according to CLSI M38-A2 guidelines [33]) was used for testing the sensitivity of the dermatophyte isolates to the most commonly used antifungal drugs. Fluconazole was obtained from Pfizer International (New York, NY, USA), itraconazole, and miconazole were obtained from the Janssen Research Foundation (Beerse, Belgium), griseofulvin was purchased from Sigma Chemical Company (St. Louis, MO, USA), 
and terbinafine was purchased from Novartis (Basel, Switzerland). All drugs were dissolved in dimethyl sulfoxide (DMSO, Sigma-Aldrich), with the exception of fluconazole, which was dissolved in RPMI1640 medium (Sigma Co. St. Louis, USA), buffered at pH 7.0 with $165 \mathrm{mM}$ of 3(N-morpholino) propanesulfonic acid (MOPS; Sigma), and serially diluted two-fold to final concentrations of $0.125-64 \mu \mathrm{g} / \mathrm{mL}$ for fluconazole and $0.03-16 \mu \mathrm{g} / \mathrm{mL}$ for the other antifungal agents. MIC values, $\mathrm{MIC}_{50}$, and $\mathrm{MIC}_{90}$ were determined.

\section{Preparation of Aloe vera gel extracts (AGEs)}

Aloe vera leaves were obtained from the Agriculture Faculty, Zagazig University, Zagazig, Egypt. Aloe vera gel was obtained from the leaves by scratching. The aqueous extract of the gel was prepared using a magnetic stirrer (Fisher Scientific) and filtered using Whatman No. 1 filter paper. The extraction ratio was $1: 5(\mathrm{~W}: \mathrm{V}$, gel:solvent). The filtrate was freeze-dried (Thermo-Electron Corporation-Heto power dry LL300 Freeze Dryer) and the extract was then weighed to decide the yield and stored at $-20^{\circ} \mathrm{C}$.

\section{Chemical characterization of AGE Determination of phenolic compounds}

The concentration of total phenols in the extract was measured by a UV spectrophotometer (Jenway-UV-VIS Spectrophotometer 6705) based on the colorimetric reduction of the reagent by phenolic compounds, as described by Škerget et al. [34]. The total phenolic content, expressed as GAE, was calculated as follows: $\mathbf{y}=\mathbf{0 . 0 2 2 8}$ $\mathrm{x}+\mathbf{0 . 0 0 8 6}$ and $\boldsymbol{R}^{2}=\mathbf{0 . 9 9 6 9}$, where $\mathrm{x}$ is the concentration $(\mu \mathrm{g} \mathrm{GAE})$ and $\mathrm{y}$ is the absorbance.

\section{Determination of total flavonoids}

Total flavonoid content, expressed as QE, in AGE at a final concentration of $1 \mathrm{mg} \mathrm{mL}^{-1}$ was calculated as follows: $\mathbf{y}=\mathbf{0 . 0 1 4 2} \mathrm{x}-\mathbf{0 . 0 0 7}$ and $\boldsymbol{R}^{\mathbf{2}}=\mathbf{0 . 9 9 9 4}$, where $\mathrm{x}$ is the concentration $(\mu \mathrm{g} \mathrm{QE})$ and $\mathrm{y}$ is the absorbance [35].

\section{Determination of phenolic compounds by HPLC}

The HPLC analysis was performed as described previously [36], with slight modifications, using an Agilent Technologies 1100 series liquid chromatograph equipped with an autosampler. The analytical column was Agilent Eclipse XDB C18 $(100 \times 4.6 \mu \mathrm{m} ; 3.5 \mu \mathrm{m}$ particle size $)$. The diode array detector was set to a scanning range of $180-420 \mathrm{~nm}$. The mobile phase consisted of methanol (solvent A) and $0.1 \%$ formic acid (v/v) (solvent B). The flow rate was kept at $0.4 \mathrm{~mL} \mathrm{~min}^{-1}$ and the gradient program was as follows: $10 \%$ A $-90 \%$ B (0-5 min); $20 \%$ A - 80\% B (5-10 min); $30 \%$ A $-70 \%$ B (10-15 min); 50\% A - 50\% B (15-20 min); $70 \%$ A $-30 \%$ B (20-25 min); $90 \%$ A $-10 \%$ B (25-30 min); $50 \%$ A $-50 \%$ B ( $30-35 \mathrm{~min})$; and $10 \%$ A - 90\% B (35-36 min). A 5 min post-run was used for reconditioning. The injection volume was $10 \mu \mathrm{L}$ and peaks were monitored simultaneously at 280,320 and $360 \mathrm{~nm}$ for the benzoic acid and cinnamic acid (Sigma, St. Louis, MO, USA) derivatives and flavonoid compounds, respectively. All samples were filtered through a $0.45 \mu \mathrm{m}$ Acrodisc syringe filter (Gelman Laboratory, MI) before injection. Peaks were identified based on congruent retention times and UV spectra and compared with those of the standards (Sigma, St. Louis, MO, USA).

\section{Antioxidant and biological activity of AGE $D P P H^{\circ}$ radical-scavenging activity}

The electron-donation ability of AGE was measured by bleaching of the DPPH ${ }^{-}$(Sigma, St. Louis, MO, USA) purple-colored solution using a UV spectrophotometer (Jenway-UV-VIS Spectrophotometer 6705) [37]. The absorbance was determined against the control at $515 \mathrm{~nm}$ [38]. The percentage of the scavenging activity of the $\mathrm{DPPH}^{*}$ free radical was calculated as follows:

$$
\begin{aligned}
& \text { Scavenging activity }(\text { Inhibition }) \% \\
& =\left[\left(\mathbf{A}_{\text {control }}-\mathbf{A}_{\text {sample }}\right) / \mathbf{A}_{\text {control }}\right] \times \mathbf{1 0 0}
\end{aligned}
$$

where $\mathrm{A}$ control is the absorbance of the control reaction and $\mathrm{A}$ sample is the absorbance in the presence of the plant extract. Gallic acid and TBHQ (Sigma, St. Louis, MO, USA) (1 mg/1 mL of methanol) were used as positive controls. Samples were tested in triplicate.

\section{$\beta$-Carotene/linoleic acid bleaching}

The ability of AGE and synthetic antioxidants (gallic aid and $\mathrm{TBHQ}$ ) to hinder the bleaching of $\beta$-carotene (Sigma, St. Louis, MO, USA) was examined according to Dastmalchi et al. [39]. A control sample with no added extract was also analyzed. Antioxidant activity was calculated as follows:

$$
\begin{aligned}
& \begin{array}{c}
\text { Antioxidant activity }(\%) \\
=\left[\mathbf{1}-\left(\mathbf{A}_{\text {sample }}^{\mathbf{0}}-\mathbf{A}_{\text {sample }}^{\mathbf{1 2 0}}\right) /\right. \\
\left.\left(\mathbf{A}_{\text {control }}^{\mathbf{0}}-\mathbf{A}_{\text {control }}^{\mathbf{1 2 0}}\right)\right] \times \mathbf{1 0 0}
\end{array}
\end{aligned}
$$

where $\mathbf{A}_{\text {sample }}^{\mathbf{0}}$ is the absorbance of the AGE or synthetic antioxidant at time $0, \mathbf{A}^{\mathbf{1 2 0}}$ sample is the absorbance after $120 \mathrm{~min}$, and $\mathbf{A}_{\text {control }}^{\mathbf{0}}$ and $\mathbf{A}^{\mathbf{1 2 0}}$ control are the absorbances of the control at time 0 and after $120 \mathrm{~min}$, respectively.

\section{Ferric reducing antioxidant power}

The reducing power of the extract was assessed [38]. Distilled water was used as a negative control and gallic acid and TBHQ were used as positive controls. The absorbance of this mixture was measured at $700 \mathrm{~nm}$ using a UV spectrophotometer (Jenway-UV-VIS 
Spectrophotometer 6705). A decrease in absorbance indicated the ferric reducing power capability of the sample.

\section{Testing the antidermatophyte activity of AGE}

The procedure of Silva et al. [40] was used to test the antidermatophyte activity of AGE. The freeze-dried AGE $(3.5 \mathrm{~g})$ was dissolved and serially two-fold diluted in RPMI-1640 broth, to obtain a concentration range of $1000-20,000 \mu \mathrm{g} / \mathrm{mL}$ as TPC. A final concentration of $50-1000 \mu \mathrm{g} / \mathrm{mL}$ was obtained by mixing $2 \mathrm{~mL}$ of this solution with $18 \mathrm{~mL}$ of liquefied Mycobiotic Agar medium $\left(\right.$ Remel $^{\mathrm{TM}}$, Thermo Fisher Scientific) at $45^{\circ} \mathrm{C}$ in a sterile Petri dish. Subsequently, wells with a diameter of $3 \mathrm{~mm}$ were made in the center of this agar plate and filled with $10 \mu \mathrm{L}$ of the fungal spore suspension $\left(10^{6} \mathrm{CFU} / \mathrm{mL}\right)$ that was prepared from freshly cultured isolates. The plates were incubated for 5 days at $25^{\circ} \mathrm{C}$. The assay was carried out in triplicate and growth and drug controls were incorporated into the test. The concentration that inhibited the fungal growth was considered as the MIC.

\section{Investigation of AGE effectiveness for the treatment of calf ringworm}

Seventy-five calves showing evident clinical signs of ringworm were used for the investigation of AGE effectiveness in comparison with antifungal drugs for the treatment of this condition after obtaining informed consent from the farm owners. The enrolled calves were positive on mycological examination and T. verrucosum was isolated from clinical samples. Sample size calculation at a 0.05 significance level and $80 \%$ power revealed that 15 calves per group (G) would have been required. Calves exhibiting an equivalent severity of lesions distributed on the head, neck, and body were allocated randomly into five groups by using random number generator. Animals in G1 were treated orally with 250 mg/day of terbinafine (Lamisil ${ }^{\circ}$; Novartis, Basel, Switzerland). The crust on the skin lesions was removed with a brush and topical miconazole (Janssen Research Foundation, Beerse, Belgium) (G2), AGE solution (500 ppm) (G3), or oral terbinafine in combination with AGE (G4) were applied twice a day for 2 weeks. Animals in G5 were left untreated (as controls). Calves were observed daily for 6 weeks. In the beginning, during and after the treatment, the clinical efficacy was assessed by scoring dermatophytosis lesions on a 0-3 scale using previously published criteria [41-43] (Additional Table 2 ). The scoring was performed by the same investigator who was blinded to the treatment groups. The scores for each evaluated area (e.g. head, neck, and body) were averaged as follows: Sum of scores assigned to all lesions on the area/ Number of lesions on this area. Average total score of each animal $=$ Sum of scores assigned to all evaluated areas/ Number of affected areas [44]. The lesions were assessed on every examination. The mycological examination was performed every week until two consecutive fungal cultures gave negative results [30, 44 ]. The control animals were treated after the observation period.

Each animal group was housed in a separate well ventilated, open sided pen with sheltered area. All the pens received similar management conditions. Area per calf in each pen was not less than $4 \mathrm{~m}^{2}$ to avoid the overcrowding. The pens were bedded with straw that was changed every 1-2 weeks and antifungal disinfection for the entire pen and all materials with which animals come in contact was performed using $0.2 \%$ enilconazole (Clinafarm ${ }^{\odot}$ EC; Merck Animal Health USA).

\section{Data analysis}

Various risk factors that were recorded on the whole set of the 760 clinically examined calves for ringworm lesions were included as independent variables in a multiple stepwise logistic regression model (PROC LOGISTIC, SAS Institute Inc. [45]). An approximate measure of relative risk was determined using odds ratio (the antilogarithm of the coefficient) with $95 \%$ confidence intervals. To confirm results and to identify the most important risk factor as a classifier that differentiated between infected and noninfected calves, a random forest non-parametric classification analysis was performed using the MetaboAnalystR web server [46]. Briefly, the occurrence of each variable was first used to build up a random forest classification model (an ensemble of 500 tree trials; out-of-bag (OOB) error $=0.6)$ in the respective outcome. The importance of the risk factor was determined by measuring the increase in the $\mathrm{OOB}$ error when the respective factor was permuted. The sensitivity, specificity, negative and positive predictive values, positive and negative likelihood ratio, and diagnostic odds ratio, which express the strength of the association between the test results and disease, with 95\% confidence intervals for direct-sample PCR assays were estimated. All diagnostic indices were predestined based on (a) culture and (b) culture and nested PCR as the gold standard for the detection/identification of dermatophytes causing calves' ringworm. The Kappa value was used to test the agreement between test results. Student's t-test was used to compare the mean MIC values \pm $\mathrm{SD}$ of each antifungal drug for the tested species. Kruskal-Wallis test was used to analyze the differences in clinical score changes among the treated and untreated groups over time after confirming the significance of Shapiro-Wilk test results [47]. The differences in clinical scores between groups were assessed by the Mann-Whitney $U$ test after a significant result on the Kruskal-Wallis test. Significance was set at $P<0.05$. 


\section{Supplementary Information}

The online version contains supplementary material available at https://doi. org/10.1186/s12917-020-02616-9.

Additional file 1: Table S1. Mean MICs $\pm S D, M I C$ range, $M I C_{50}$, and $\mathrm{MIC}_{90}$ values of antifungal drugs for $T$. verrucosum and T. mentagrophytes isolates.

Additional file 2: Table S2. Scoring of ringworm lesions in calves according to Moriello et al. 2004; Lund and DeBoer, 2008; and Balikci et al. 2016.

Additional file 3: Fig. S1. Ringworm in calves due to T. verrucosum with typical grey-white raised crusty lesions on head and neck regions (A) and extensive alopecia, erythema, and scales that remained after removal of thick greasy crusts firmly attached to erect and matted hair over the back (B).

Additional file 4: Fig. S2. Treatment of ringworm in calf with 500 ppm topical AGE (A) calf at day 0 before treatment and (B) after 20 days posttreatment.

\section{Abbreviations}

ITS: Internal transcribed spacers regions of ribosomal DNA; pchs-1: Partial chitin synthase; MIC: Minimum Inhibitory Concentration; AGE: Aloe vera gel extract; TPC: Total phenolic compounds; TF: Total flavonoids; QE: Quercetin equivalent; GAE: Gallic acid equivalent; PPV: Positive predictive value; NPV: Negative predictive value; AUC: Accuracy; DOR: Diagnostic odds ratio; LR: Likelihood ratio

\section{Acknowledgments}

Authors thanks Dr. Hager F. Gouda, Animal Wealth Department, Faculty of Veterinary Medicine, Zagazig University, Zagazig, Egypt, for her contribution to statistical analysis.

\section{Authors' contributions}

$Y T$, WE, AM, MA, RM, HD, HM contributed to the study design and the execution of experiments. WE, AM collected the samples. YT analyzed MIC and DNA sequence data and drafted the manuscript. MA was responsible for the chemical characterization of AGE. YT, WE, AM, MA, RM, HD, HM contributed to the acquisition, analysis, and interpretation of data. All authors read and approved the submitted version of the manuscript

\section{Funding}

This research did not receive any specific grant from funding agencies in the public, commercial, or not-for-profit sectors.

\section{Availability of data and materials}

The datasets generated and/or analysed during the current study are available in the GenBank under accession numbers: MK918485, MK918486, MT261760-MT261763, MT261765-MT261768, MT260175, MT260404, MT260449, MT260803, MT273253-MT273262, MT260878, MT261110, MT261113, MT261177, MT261197, MT261198, MT261202, MT261203, MT261385, MT261616, MT261746, MT261759, and MT269023.

\section{Ethics approval and consent to participate}

The protocol of this study was approved by the Ethical Committee on animal care and use Experimentation in Zagazig University (ZU-IACUC/2/F/ $11 / 2018)$. Written informed consent was obtained from the farm owners for the treatment of calves showing clinical signs of ringworm.

\section{Consent for publication}

Not applicable.

\section{Competing interests}

Authors have no competing interests to declare.

\section{Author details}

${ }^{1}$ Department of Microbiology, Faculty of Veterinary Medicine, Zagazig University, Zagazig 44511, Egypt. ${ }^{2}$ Infectious Diseases, Department of Animal Medicine, Faculty of Veterinary Medicine, Zagazig University, Zagazig 44511, Egypt. ${ }^{3}$ Department of Zoonoses, Faculty of Veterinary Medicine, Zagazig

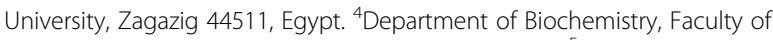
Agriculture, Zagazig University, Zagazig 44511, Egypt. ${ }^{5}$ Department of Veterinary Public Health, Faculty of Veterinary Medicine, Zagazig University, Zagazig 44511, Egypt. ${ }^{6}$ Department of Animal Wealth, Faculty of Veterinary Medicine, Zagazig University, Zagazig 44511, Egypt.

Received: 25 September 2019 Accepted: 9 October 2020

Published online: 04 November 2020

\section{References}

1. Seyedmousavi S, Guillot J, Tolooe A, Verweij PE, de Hoog GS. Neglected fungal zoonoses: hidden threats to man and animals. Clin Microbiol Infect. 2015;21:416-25. https://doi.org/10.1016/j.cmi.2015.02.031.

2. Chermette R, Ferreiro L, Guillot J. Dermatophytoses in animals. Mycopathologia. 2008;166:385-405. https://doi.org/10.1007/s11046-0089102-7.

3. Shams-Ghahfarokhi M, Mosleh-Tehrani F, Ranjbar-Bahadori S, RazzaghiAbyaneh M. An epidemiological survey on cattle ringworm in major dairy farms of Mashhad city, Eastern Iran. Iran J Microbiol. 2009;1:31-6.

4. Papini R, Nardoni S, Fanelli A, Mancianti F. High infection rate of Trichophyton verrucosum in calves from Central Italy. Zoonoses Public Health. 2009;56:59-64. https://doi.org/10.1111/j.1863-2378.2008.01157.x.

5. Aghamirian MR, Ghiasian SA. Dermatophytes as a cause of epizoonoses in dairy cattle and humans in Iran: epidemiological and clinical aspects. Mycoses. 2011;54:52-6. https://doi.org/10.1111/j.1439-0507.2009.01832.x.

6. Monod M, Fratti M, Mignon B, Baudraz-Rosselet F. Dermatophytes transmitted by pets and cattle. Rev Med Suisse. 2014;10:749-53.

7. Cafarchia C, Gasser RB, Figueredo LA, Weigl S, Danesi P, Capelli G, et al. An improved molecular diagnostic assay for canine and feline dermatophytosis. Med Mycol. 2013;51:136-43. https://doi.org/10.3109/13693786.2012.691995.

8. Tartor YH, El Damaty HM, Mahmmod YS. Diagnostic performance of molecular and conventional methods for identification of dermatophyte species from clinically infected Arabian horses in Egypt. Vet Dermatol. 2016; 27:401-e102. https://doi.org/10.1111/vde.12372.

9. Lopes G, Pinto E, Salgueiro L. Natural products: an alternative to conventional therapy for dermatophytosis? Mycopathologia. 2017;182:14367. https://doi.org/10.1007/s11046-016-0081-9.

10. Kumar S, Yadav M, Yadava A, Yadav JP. Comparative analysis of antimicrobial activity of methanolic extracts of Aloe Vera and quantification of Aloe- Emodin collected from different climatic zones of India. Arch Clin Microbiol. 2015;6:1-10. https://doi.org/10.1002/pssc.200982739.

11. Agnetti F, Righi C, Scoccia E, Felici A, Crotti S, Moretta I, et al. Trichophyton verrucosum infection in cattle farms of Umbria (Central Italy) and transmission to humans. Mycoses. 2014;57:400-5. https://doi.org/10.1111/ myc.12174.

12. Hameed K, Ch FR, Nawaz MA, Naqvi SMS, Gräser Y, Kupsch C, et al. Trichophyton verrucosum infection in livestock in the Chitral district of Pakistan. J Infect Dev Ctries. 2017;11:326-33. https://doi.org/10.3855/jidc.7925.

13. Tartor YH, E Y EL-N, Gharieb NM, Ali WS, Ammar AM. Novel Streptococcus equi strains causing strangles outbreaks in Arabian horses in Egypt. Transbound Emerg Dis. 2020:1-12. https://doi.org/10.1111/tbed.13584.

14. Rochette $F$, Engelen $M$, Vanden $B H$. Antifungal agents of use in animal health - practical applications. J Vet Pharmacol Ther. 2003;26:31-53. https:// doi.org/10.1046/j.1365-2885.2003.00457.x.

15. Nweze El. Dermatophytoses in domesticated animals. Rev Inst Med Trop Sao Paulo. 2011:53:95-9. https://doi.org/10.1590/s0036-46652011000200007.

16. Swai ES, Sanka PN. Bovine dermatophytosis caused by Trychophyton verrucosum: a case report. Vet World. 2012;5:297-300. https://doi.org/10. 5455/vetworld.2012.297-300.

17. Wollina U, Hansel G, Uhrlaß S, Krüger C, Schönlebe J, Hipler UC, et al. Deep facial mycosis due to Trichophyton verrucosum-molecular genetic identification of the dermatophyte in paraffin-embedded tissue-case report and review of the literature. Mycoses. 2018;61:152-8. https://doi.org/ 10.1111/myc.12719.

18. Piri F, Mahmoudabadi AZ, Ronagh A, Ahmadi B, Makimura K, RezaeiMatehkolaei A. Assessment of a pan-dermatophyte nested-PCR compared with conventional methods for direct detection and identification of dermatophytosis agents in animals. Mycoses. 2018;61:837-44. https://doi. org/10.1111/myc.12821. 
19. Chandran NS, Pan J-Y, Pramono ZA, Tan H-H, Seow C-S. Complementary role of a polymerase chain reaction test in the diagnosis of onychomycosis. Australas J Dermatol. 2013;54:105-8. https://doi.org/10.1111/ajd.12027.

20. Spiliopoulou A, Bartzavali C, Jelastopulu E, Anastassiou ED, Christofidou M. Evaluation of a commercial PCR test for the diagnosis of dermatophyte nail infections. J Med Microbiol. 2015;64:25-31. https://doi.org/10.1099/jmm.0. 079962-0.

21. Magagnin CM, Stopiglia CDO, Vieira FJ, Heidrich D, Machado M, Vetoratto G, et al. Antifungal susceptibility of dermatophytes isolated from patients with chronic renal failure. An Bras Dermatol. 2011;86:694-701. https://doi.org/10. 1590/s0365-05962011000400011.

22. El Damaty HM, Tartor YH, Mahmmod YS. Species identification, strain differentiation, and antifungal susceptibility of dermatophyte species isolated from clinically infected Arabian horses. J Equine Vet Sci. 2017;59. https://doi.org/10.1016/j.jevs.2017.08.019.

23. Pal M. Dermatophytosis in an adult cattle due to Trichophyton verrucosum. Anim Husb, Dairy Vet Sci. 2017;1:1-3. https://doi.org/10.15761/ahdvs. 1000106.

24. Flores-López ML, Romaní A, Cerqueira MA, Rodríguez-García R, Jasso de Rodríguez D, Vicente AA. Compositional features and bioactive properties of whole fraction from Aloe vera processing. Ind Crop Prod. 2016;91:179-85. https://doi.org/10.1016/j.indcrop.2016.07.011.

25. Mullen W, Marks SC, Crozier A. Evaluation of phenolic compounds in commercial fruit juices and fruit drinks. J Agric Food Chem. 2007;55:314857. https://doi.org/10.1021/jf062970x.

26. Osawa T. Novel natural antioxidants for utilization in food and biological systems. Post Harvest Biochemical plant food-materials in theTropics. Tokyo: Japan Scientific Press; 1994. p. 241-51.

27. Pereira A, Ferreira I, Marcelino F, Valentão P, Andrade P, Seabra R, et al Phenolic compounds and antimicrobial activity of olive (Olea europaea L. (v. Cobrançosa) leaves. Molecules. 2007;12:1153-62. https://doi.org/10.3390/ 12051153

28. Liu RH. Health benefits of fruit and vegetables are from additive and synergistic combinations of phytochemicals. Am J Clin Nutr. 2003;78:517S20S. https://doi.org/10.1093/ajcn/78.3.517S.

29. Adejumo TO, Bamidele BS. Control of dermatophyte-causing agents (Trichophyton mentagrophytes and Trichophyton rubrum) using six medicinal plants, vol. 3; 2009. p. 906-13.

30. Çam Y, Koç AN, Silici S, Günes V, Buldu H, Onmaz AC, et al. Treatment of dermatophytosis in young cattle with propolis and whitfield's ointment. Vet Rec. 2009;165:57-8.

31. Gupta VK, Mahendran K, Pathak R, Ramkumar PK, Kumar ORV. Clinical management of dermatophytosis in calves. Intas Polivet. 2013;14:333-5.

32. Campbell CK, Johnson EM, Philpot CM, Warnock DW. The dermatophytes. In: Identification of pathogenic fungi. London: PHLS; 1996. p. 26-68.

33. Clinical and Laboratory Standards Institute. M38-A2 Reference Method for Broth Dilution Antifungal Susceptibility Testing of Filamentous Fungi; Approved Standard. 3rd ed. Wayne: CLSI standard M38; 2017.

34. Škerget $M$, Kotnik $P$, Hadolin M, Hraš AR, Simonič M, Knez Ž. Phenols, proanthocyanidins, flavones and flavonols in some plant materials and their antioxidant activities. Food Chem. 2005:89:191-8.

35. Ordoñez AAL, Gomez JD, Vattuone MA, MI I. Antioxidant activities of Sechium edule (Jacq.) Swartz extracts. Food Chem. 2006;97:452-8. https:// doi.org/10.1016/J.FOODCHEM.2005.05.024.

36. Sati $P$, Dhyani $P$, Bhatt ID, Pandey A. Ginkgo biloba flavonoid glycosides in antimicrobial perspective with reference to extraction method. J Tradit Complement Med. 2019;9:15-23. https://doi.org/10.1016/j.jtcme.2017.10.003.

37. Hatano T, Kagawa H, Yasuhara T. OkudaT. Two new flavonoids and other constituents in licorice root. Their relative astringency and radical scavenging effects. Chem Pharm Bull (Tokyo). 1988;36:2090-7. https://doi. org/10.1248/cpb.36.2090

38. Gülçin İ, Bursal E, Şehitoğlu MH, Bilsel M, Gören AC. Polyphenol contents and antioxidant activity of lyophilized aqueous extract of propolis from Erzurum, Turkey. Food Chem Toxicol. 2010;48:2227-38. https://doi.org/10. 1016/j.fct.2010.05.053.

39. Dastmalchi K, Damien Dorman HJ, Laakso I, Hiltunen R. Chemical composition and antioxidative activity of Moldavian balm (Dracocephalum moldavica L.) extracts. LWT Food Sci Technol. 2007:40:1655-63. https://doi. org/10.1016/J.LWT.2006.11.013.
40. Silva MRR, Oliveira JG, Fernandes OFL, Passos XS, Costa CR, Souza LKH, et al. Antifungal activity of Ocimum gratissimum towards dermatophytes. Mycoses. 2005;48:172-5. https://doi.org/10.1111/j.1439-0507.2005.01100.x.

41. Moriello KA, Deboer DJ, Schenker R, Blum JL, Volk LM. Efficacy of pretreatment with lufenuron for the prevention of Microsporum canis infection in a feline direct topical challenge model. Vet Dermatol. 2004;15:357-62.

42. Lund A, Deboer DJ. Immunoprophylaxis of dermatophytosis in animals. Mycopathologia. 2008;166:407-24.

43. Balikci E. Antidermatophyte and antioxidant activities of Nigella sativa alone and in combination with enilconazole in treatment of dermatophytosis in cattle, vol. 2016; 2016. p. 539-45.

44. Ural K, Ulutas B. Immunization with Trichophyton verrucosum vaccine in hunter/jumper and dressage horses with naturally occurring Trichophyton equinum infection: a prospective, randomized, double-blinded, placebocontrolled clinical trial. J Equine Vet Sci. 2008;28:590-3. https://doi.org/10. 1016/j.jevs.2008.08.009.

45. SAS Institute Inc. SAS User Guide: Statistics, Version 5. Cary: SAS Institute Inc:; 2012.

46. Chong J, Xia J. MetaboAnalystR: an R package for flexible and reproducible analysis of metabolomics data. Bioinformatics. 2018;34:4313-4. https://doi. org/10.1093/bioinformatics/bty528.

47. Razali NM, Wah YB. Power comparisons of Shapiro-Wilk, Kolmogorov-Smirnov, Lilliefors and Anderson-Darling tests. J Stat Model Anal. 2011;2:21-33.

\section{Publisher's Note}

Springer Nature remains neutral with regard to jurisdictional claims in published maps and institutional affiliations.
Ready to submit your research? Choose BMC and benefit from:

- fast, convenient online submission

- thorough peer review by experienced researchers in your field

- rapid publication on acceptance

- support for research data, including large and complex data types

- gold Open Access which fosters wider collaboration and increased citations

- maximum visibility for your research: over $100 \mathrm{M}$ website views per year

At BMC, research is always in progress.

Learn more biomedcentral.com/submissions 